Journal of

Child Health Care

\title{
Using participatory drama workshops to explore children's beliefs, understandings and experiences of coming to hospital for clinical procedures.
}

\begin{tabular}{|r|l|}
\hline Journal: & Journal of Child Health Care \\
\hline Manuscript ID & JCHC-2019-0111.R3 \\
\hline Keyword: & children, procedures, involvement, decisions \\
\hline & $\begin{array}{l}\text { Children attending hospital for a clinical procedure such as a scan or } \\
\text { blood test can experience anxiety and uncertainty. Children who are } \\
\text { informed and supported before and during procedures tend to have a } \\
\text { more positive experience. Despite this there is a lack of empirical } \\
\text { evidence directly from children around how they would like to be } \\
\text { supported before, during and after a procedure. This qualitative study } \\
\text { used improvised drama workshops to investigate children's ( } \mathrm{n}=15, \text { aged } \\
\text { 7-14 years) perceptions and opinions of attending hospital for a } \\
\text { procedure and what would help them have a positive encounter. Children } \\
\text { portrayed themselves as having a small presence during a hospital } \\
\text { procedure; depicted by the two themes of 'having to be brave but feeling } \\
\text { scared inside' and 'wanting to get involved but being too afraid to ask'. } \\
\text { Within both themes children described how the directive and reassuring } \\
\text { language and actions used by health professionals and parents } \\
\text { marginalised their contributions. This study shows that children } \\
\text { attending hospital for procedures value the opportunity to have a } \\
\text { presence and active role, to express their emotions, join in interactions } \\
\text { and be involved in making choices about their care. }\end{array}$ \\
\hline Abstractions
\end{tabular}

\section{SCHOLARONE Manuscripts}




\title{
Using participatory drama workshops to explore children's beliefs, understandings and experiences of coming to hospital for clinical procedures.
}

\begin{abstract}
Children attending hospital for a clinical procedure such as a scan or blood test can experience anxiety and uncertainty. Children who are informed and supported before and during procedures tend to have a more positive experience. Despite this there is a lack of empirical evidence directly from children around how they would like to be supported before, during and after a procedure. This qualitative study used improvised drama workshops to investigate children's ( $n=15$, aged 7-14 years) perceptions and opinions of attending hospital for a procedure and what would help them have a positive encounter. Children portrayed themselves as having a small presence during a hospital procedure; depicted by the two themes of 'having to be brave but feeling scared inside' and 'wanting to get involved but being too afraid to ask'. Within both themes children described how the directive and reassuring language and actions used by health professionals and parents marginalised their contributions. This study shows that children attending hospital for procedures value the opportunity to have a presence and active role, to express their emotions, join in interactions and be involved in making choices about their care.
\end{abstract}

\section{Introduction}

It is well established that children attending hospital for a clinical procedure such as a scan, blood test or examination can experience anxiety (Jaaniste et al., 2007; Duff et al., 2012) and fear (Heden et al., 2016; Dalley \& McMurtry 2016) before, during and after their procedure. There is evidence that children who are well informed about what will happen during a clinical procedure and are supported throughout their procedure have a better experience (Bray et al 2019), have lower levels of anxiety and stress (Copanitsanou \& Valkeapää 2014; Duff et al., 2012) and are less likely to be held against their will in order for their procedure to be completed (Bray et al., 2016).

Despite the evidence highlighting the positive outcomes for children who are informed and supported when undergoing procedures; there is a lack of empirical evidence directly from children around how they can be best supported before, during and after clinical procedures such as X-rays, blood tests and examinations. The current evidence shows that children attending hospital for procedures value information about what will happen during their visit or admission (Coyne \& Kirwan 2012; Lambert et al., 2013) and can identify their information needs relating to procedures (Bray et al., 2019). Children value health professionals who communicate directly and honestly with them (Brady, 2009) involve them in choices and decisions about their care (Coyne, 2006; Lambert et al., 2008; Moore \& Kirk 2010; Coyne \& 
Kirwan 2012) and offer them praise (Brady, 2009). Despite there being increased awareness of the value of preparing children for procedures and involving them in their care, children's presence, opinions and contributions can be overwhelmed by the adults within hospital settings (Lambert et al., 2008, Bray et al., 2016).

This study aimed to develop a deeper understanding of what children want in terms of information, preparation and support to help them have positive encounters in hospital. In particular as researchers, we were interested in:

- Children's information needs prior to and during clinical procedures;

- What children perceive would make a clinical procedure a more positive experience for them;

- How children think they could ensure their opinions and choices relating to clinical procedures are heard by their parents.

- How children think they could ensure their opinions and choices relating to clinical procedures are heard by health professionals.

\section{Research Design}

This qualitative project used drama as a creative and participatory research method. Veale (2005, pg 254) describes approaches such as drama as a 'constructivist tool as it is a creative method that supports research participants to describe, explore and construct their experiences and give meaning to them'. Our approach was underpinned by the recognition that children's agency and participation in research can be promoted by the use of creative methodologies (Veale 2005; Carter \& Ford 2013). The participatory drama methods enabled us to work with children to generate knowledge and engage in shared group discovery rather than extracting information from them (Yardley, 2014; Haijes \& van Thiel 2016). The creative drama activities aimed to engage children actively in 'doing something' (O'Kane, 2000) and encourage active participation (Gallagher \& Gallagher 2008).

\section{Research Method}

Two drama workshops were held on the same day (morning and afternoon) and were facilitated by an experienced drama teacher. The activities were the same for both workshops. Before any drama activities commenced the roles of all the adults present were discussed and ground rules were established between those present, these included turning electronic devices to silent, agreeing to not take any images during the workshop and respecting other people's opinions and expressions. The workshops followed Yardley's (1995) guidance on the use of drama as a research method by ensuring that the context of each activity was outlined to the children to ensure that the creative process was focussed; in this case on visiting hospital for a procedure. 
The starting point for each drama activity was a scene detailed by the researchers and from this the children and young people directed the creative process through improvised performance. The drama workshops were structured around three activities; the first activity asked children to choose one of the scenes (table 1), allocate roles and 'act out' what might happen during one of the procedures. The second activity revisited these scenes and built focussed expression and improvisation around the following time points; on the way to hospital for a procedure, waiting for a procedure, having a procedure and after a procedure. The third activity was based around a hot seat idea, where the children were asked to pretend to be a doctor, nurse, radiologist, parent or child within a certain scene and respond to questions from the other children from this person's perspective. Throughout the three activities we employed techniques such as freeze-framing, as described by Veale (2005), to focus on the actors and their feelings, responses and motivations at that point in the story. The children also had access to some props including some medical play equipment (bandages, plasters, stethoscope), different hats, coats, and teddies. The children were encouraged to act out fictitious roles and imagine they were someone else. This theatrical distance aimed to free them from constraints of embarrassment or invasion of privacy (Armstrong et al., 2004), although it was evident in some of the activities that they drew heavily on their own experiences of visiting hospital. This was apparent when children commented during freeze frames that "my mum always says that when we go to hospital" or "I am acting bored, cos you always have to wait for ages".

\section{Insert Table 1 here}

Throughout the drama activities, we recorded semi-structured, paper-based field notes to capture the words used by the children and the expressions and interactions portrayed (dialogue, phrases and sketched images of scenes). The researchers ( $x x, x x, x x)$ who were present, as observers, positioned themselves unobtrusively around the large space and did not engage in the drama activities. An illustrator recorded the visual minutes of the drama workshop (Figure 1) on a large piece of paper attached to one of the walls of the room. The children commented on the illustrations and notes at the end of the workshop. We did not formally collect health related information.

The workshops were not audio-recorded as the movement and noise throughout the sessions would not have supported good sound quality.

\section{Sampling and recruitment.}

Children aged 7-14 years were recruited through flyers distributed through drama teachers at local children's drama groups and through a dedicated project social media account on Facebook. All children needed to have some experience of going to see a doctor, nurse or 
hospital experience. If the children were interested in taking part, their parents contacted the researchers who provided detailed information sheets and answered any questions the children or parents had about participation.

\section{Ethics Approval.}

The research study was granted ethics approval by the Faculty of Health and Social Care Research Ethics Committee (FREC CYPF10). All children provided written assent to participate in the drama workshops and their parents provided written consent. We ensured that the drama space was safe and accessible and there were additional rooms for breaks or quiet time. Clear actions had been identified to support any of the children who might become upset during or after the drama activities. At the end of the workshop, we spent some time 'winding down' and chatting informally over refreshments and one of the research team checked that all the children were okay in case any had been overwhelmed by the experience before they left with their parent/carer.

\section{Analysis}

We used our detailed field notes as qualitative data and did not formally transcribe the dramas. Thematic analysis involved the comparison and contrast of the shared perspectives of the children and supported the team in identifying, analysing, and reporting patterns (themes) (Braun \& Clarke 2006). We coded the actions and non-verbal expressions of the children as well as the verbal dialogue and language shared as part of the workshop. Analysis was conducted initially independently by all members of the research team ( $x x x, x x, x x)$ to identify codes based on their own field notes and then the team collaboratively discussed and debated the codes to achieve consensus on the themes.

The child's actual age, gender or participant number have not been reported alongside quotes in this paper, as children were often imagining or acting out being a different person or age in their dramatic rendition.

\section{Findings}

Fifteen children aged 7-14 years participated in the drama workshops. The children had a range of hospital experiences from minor procedures (e.g. ECG and X-ray) to lengthy inpatient stays (e.g. surgery and chemotherapy); they shared these experiences freely within the workshop.

\section{Insert table 2 here}

Two themes of 'having to be brave but feeling scared inside' and 'wanting to get involved but feeling too afraid to ask' were generated. These both involved children feeling 'small and scared'; being a 'small presence' both physically, emotionally and transactionally.

\section{"Having to be brave but feeling scared inside"}


This theme presents the portrayed emotions and feelings of children attending hospital for a procedure and then the responses of adults (parents and health professionals) to these emotions and feelings.

Many of the scenes were woven together by the children using the words "worried", "scared", "anxious", "fear", "sick" and "nervous" to portray their feelings before and during clinical procedures. These feelings of anxiety, fear and worry were depicted equally in the scenes with non-invasive procedures such as an X-ray as they were for invasive procedures such as a blood test.

In some cases children openly expressed feelings of anxiety such as acting a child crying or biting their nails, whilst some other children and young people acknowledged that they would just keep their feelings inside.

"I am not saying I am scared and worried, I am just sitting quietly - but this does not mean I am okay"

Some scenes with older children involved them purposefully hiding or disguising their feelings of being scared, as they felt they would be judged by health professionals for "not being grown up enough".

"Because I was older they were like just do it anyway. They are like why are you scared cos you are older and younger people are getting it done"

Some of the children's anxiety was heightened by their beliefs that they would be told off for their injury by health professionals, with doctors saying to them "you should have been more careful", and by the "waiting around" which accompanied a visit to hospital for a procedure. In some cases children felt they "waited so long we could have played a whole board game" and this meant that they had "more time to be scared when you just want it over and done with".

Health professionals and parents were often portrayed as being dismissive of children's feelings of anxiety or fear, with the adults' language centred on telling children to "just be brave" and to "get on with it". In one scene the group depicted a child reluctant to have an operation, where the child's expressed feelings were quickly dismissed.

"Child: I...I don't want an operation I am scared

Doctor: 4 year olds don't even cry so put the tears away."

Often health professionals and parents responded to children's expressions of fear or anxiety with a statement of reassurance such as "don't worry it will be alright" "everything will be okay" "it will be okay", "you will be okay" and "you are going to be fine". When we freeze framed the action and explored how these statements made the children feel, they stated that they would not help to reduce any anxiety or worry about what was happening. Adult reassurance through statements like "you will be okay" seemed to close down children's expressions of concern, rather than open up conversation about what might be causing them to be worried or scared. It was interesting that when the children participated in the hot seat activity and adopted the role of a doctor they then used reassurance, albeit in some cases 
with information provision as well, when talking to a child, "I would explain to a child what is going to happen and tell them it will be okay and not as bad as they think it will be".

\section{"Wanting to get involved but being too afraid to ask."}

Many of the scenes involved children acting out a seemingly invisible part in the procedures. This started at the receptionist counter where a child's name was "given in" by their parent, through to "sitting nicely" and quietly while waiting to be seen to during the procedure where health professionals directed questions and instructions towards their parent. Many of the scenes involved the children depicting themselves as peripheral to the conversation during the procedure or the health professionals using complex medical terminology.

The children who acted being children on the hot seat were questioned about what might make it better for children coming to hospital for procedures. Many answered that "feeling able to ask questions" and "being able to understand" would help them worry less and have a better experience when they came to hospital. Children wanted health professionals to "use language which I can understand - and ask me not my mum". It was important for health professionals to be honest and open in their communication, children wanted doctors to tell the truth and "don't say it won't hurt if it will", "just be honest and say it might just hurt a bit" and "it will just be a scratch". Some of the children stated that "sometimes I like mum and dad to answer questions for me" but they wanted this to be their decision.

In some instances children depicted dialogue with health professionals who were not "really listening".

\section{"Doctor: Is it hurting?}

Child: A bit

Doctor: Perfect okay when you have had this you are free to go."

This inactive listening made it hard for children to get involved in conversations and choices about their health care. These were not necessarily big treatment decisions or the need to become involved in long consultations but the children stated that it was nice to make choices like "having the curtains open or shut". These choices helped children feel listened to and valued whilst in hospital.

\section{Discussion}

Conducting research using drama helped us "re-look" (Norris, 2000, pg 41) at an area of children's health care. To the best of our knowledge, this is the first report of drama being used as a creative and participatory research method to gain understanding and meaning from the perspectives of children about hospital experiences. The use of drama and the creation of scenes became more than a research method in this study, it provided a useful lens to help us consider the parts, roles and performances children, parents and health professionals play during hospital procedures. Other studies have also considered how the delivery (or act) of health care is laced with roles and performances (Murphy, 2009; Holmes 
1992). Case and Brauner (2010, pg 160) discuss that framing health professionals as performers does not accuse them of 'fakery', but acknowledges that learned behaviours and sometimes 'scripts' of dialogue underpin much of health care practice. These 'scripts' are influenced by physical scenes (operating theatres, wards, consulting room), costumes (white coats, hospital gowns) and props (medical equipment), but also by cultural and social expectations of the roles that exist within the health service as an institution (Murphy, 2009).

Many of the drama scenes created by the children began with their journey to hospital and waiting to be seen, they depicted this as a worrying and anxious time as they did not know what would happen during their procedure. By being unprepared, children were not provided with the opportunity to understand the 'script' of the procedure, to rehearse their part or practice their lines. They had to improvise their 'performance' in an environment (hospital) in which they were unfamiliar, responding to the other actors (parents and health professionals) around them. This lack of opportunity to prepare and become informed has been linked to poorer experiences of attending hospital (Claar et al., 2002, Jaaniste et al., 2007; Bray et al., 2019) and is likely to influence children's ability to enact their agency within these interactions (Coyne \& Gallagher 2011; Bray at al., 2012; Dai \& Livesey 2018).

Within many of the scenes, children depicted themselves as having a small role with only a few lines or a non-speaking part akin to a minor 'walk-on' actor. The leading roles in the scenes, and most of the lines (dialogue) were commonly ascribed to the health professionals or parents. Health professionals were portrayed as in control or "bossy", and in some cases the children gave them the role of the director of the performance; telling the actors (parents but mainly children) where to stand and what to do. Although we know that children often wish to be involved more in health care interactions (Alderson 2007; Lambert et al., 2008; Bray et al., 2018), these drama performances suggest that children still perceive they are overshadowed (Livesey \& Long 2013) and excluded (Coyne \& Gallagher 2011) by their parents and health professionals during health care procedures. Children were portrayed as bystanders at their own appointment. It is worthy to note that the children in this study often discussed health professionals and parents as a collective "they" in relation to the perceived dominant roles and the use of directive and reassuring language during a procedure.

In scenes where dialogue occurred with children, or children expressed uncertainty or anxiety, key phrases from health professionals and parents such as "you need to be brave" and "you will be okay" were portrayed as quickly closing down children's interactions. These phrases were delivered as directions and were often not accompanied with any guidance or exploration around what was causing children to be worried or anxious. There is a poor understanding of how the use of language during children's health care procedures influences their experiences and outcomes. However, there is some evidence which indicates that the use of re-assurance through phrases such as "you will be fine" can increase children's anxiety (Taylor et al., 2011; McMurtry et al., 2010; Jaaniste et al., 2007), which seems to be mirrored in the data from this study. 
All of the acted out procedures ended abruptly; the child was 'dismissed' from the room. In some scenes a child was offered a sticker on their way out and all the actors (child, parent and health professional) portrayed a collective sense of relief. There has been little attention paid in the literature to the end of a clinical procedure or what happens 'afterwards'. However, there is some evidence that children are often quick to leave the 'scene' with minimal de-brief or discussion with their parent/s or health professional/s (Bray et al., 2016). There is an emerging understanding that the language used by health professionals after a needle procedure can help re-frame a child's memory of the event and improve subsequent pain experiences (Noel et al., 2018). There is more work to be done to investigate the influence of language and interaction before, during and after a clinical procedure from children's perspectives.

\section{Critique of drama research method}

Drama as a creative and participatory method seems to have been used infrequently within health research. To date, the use of drama with children has been mainly confined to the fields of psychotherapy, arts therapy and educational settings (Veale, 2005). Our approach was not to use drama to help children find resolution (Veale, 2005) or for therapeutic benefit, but as a method to help them explore and construct stories and acts about hospital procedures. We were mindful in our approach to reduce the risk of harm as a result of the children revisiting difficult or distressing situations (Dokter, 2016), so we directed children to act out fictitious roles and parts, although in some cases they discussed how they had drawn on their own personal experiences. As described by Veale (2005), the delineation between reality and make-believe in drama methods can be difficult to orchestrate. Within the workshops if children had begun to re-enact their personal experiences or portray identifiable people we would have gently intervened to re-direct the performances. Time was spent at the end of the drama workshops undertaking an informal debrief. This debrief was important as it helped the children step out of role (Yardley, 1995) and talk through any issues before leaving the workshop. All the children who participated in the workshops reported that they enjoyed the experience.

We acknowledge how the choice of drama as a research method will have shaped the data, as is the case for many arts based participatory approaches (Gallagher \& Gallagher 2008; Coyne \& Carter 2018). Adults shaped the focus of the session as the children responded to and acted out performances based on the broad scenes provided by the researchers, although there was freedom within the session for the children to develop their own ideas and adapt and shape their productions outside the boundaries of the set scenes. We embraced the flexibility and unpredictability of researching with children as described by Gallagher \& Gallagher (2008) whilst ensuring the children were clear what they were 'signing up' to take part in. Although children may be more comfortable with creative methods than more formal data collection methods we acknowledge that the use of drama may have favoured more confident children (Armstrong et al., 2004). 


\section{Implications for Practice}

These findings highlight that children think there is still some way to go to ensure that they are adequately prepared, involved and supported throughout their hospital procedure. Children should be supported to know what will happen when they come for a procedure and health professionals and parents should make sure that their interactions with children are not dominated by words of reassurance or direction. We hope that freely accessible resources (https://www.edgehill.ac.uk/childrencomingtohospital/) will educate healthcare professionals and parents in how to better support children coming to hospital for a procedure.

\section{Conclusion}

This study has illustrated that children continue to feel like a 'small presence' during clinical procedures. Interactions were portrayed as being dominated by the directional and/or reassuring language of their parents and health professionals; this limited children's opportunities to gain information and get meaningfully involved. There is further work to be done to ensure that children have the opportunity before, during and after their procedure to express their emotions, be prepared, join in conversations and be involved in making choices about their care.

\section{Acknowledgements}

We would like to thank all the children who participated in the participatory drama workshops and shared their ideas, experiences and creativity.

\section{References}

Alderson, P. (2007) Competent children? Minors' consent to health care treatment and research. Social Science \& Medicine, 65(11), 2272-2283.

Armstrong, M., Boyden, J., Galappatti, A., \& Hart, J. (2004). Piloting methods for the evaluation of psychosocial programme impact in Eastern Sri Lanka final report for USAID. Refugee Studies Centre: Oxford University (March). https://resourcecentre.savethechildren.net/sites/default/files/documents/2685.pdf [accessed 15/12/18]

Brady, M. (2009) Hospitalized children's views of the good nurse. Nursing ethics, 16(5), 543-560.

Braun, V. \& Clarke, V. (2006) Using thematic analysis in psychology. Qualitative research in psychology, 3(2), 77 101

Bray, L., Callery, P. \& Kirk, S. (2012) A qualitative study of the pre-operative preparation of children, young people and their parents' for planned continence surgery: experiences and expectations. Journal of Clinical Nursing, 21(13-14), 1964-1973.

Bray, L., Carter, B. \& Snodin, J. (2016) Holding children for clinical procedures: perseverance in spite of or persevering to be child-centered. Research in nursing \& health, 39(1), 30-41.

Bray, L., Maden, M., Bewley, T. \& Carter, B. (2018) A systematic evidence synthesis of interventions to engage children and young people in consultations about their long-term conditions. Journal of Child Health

Care, 22(1), 122-146 
Bray, L., Appleton, V \& Sharpe, A (2019) The information needs of children having clinical procedure in hospitals. Will it hurt? Will I feel scared? What can I do to stay calm? Child: Care, Health and Development 45(5), 737-743

Bray, L., Appleton, V. and Sharpe, A., 2019. 'If I knew what was going to happen, it wouldn't worry me so much': Children's, parents' and health professionals' perspectives on information for children undergoing a procedure. Journal of Child Health Care, https://doi.org/10.1177/1367493519870654

Carter, B. \& Ford, K., 2013. Researching children's health experiences: The place for participatory, child-centered, arts-based approaches. Research in Nursing \& Health, 36(1), 95-107.

Case, G.A \& Brauner, D.J (2010) The Doctor as Performer: A Proposal for Change Based on a Performance Studies Paradigm. Academic Medicine, 85 (1) 159-163

Claar, R.L., Walker, L.S. and Barnard, J.A., (2002). Children's knowledge, anticipatory anxiety, procedural distress, and recall of esophagogastroduodenoscopy. Journal of Pediatric Gastroenterology and Nutrition, 34(1), 68-72.

Copanitsanou, P. \& Valkeapää, K. (2014) Effects of education of paediatric patients undergoing elective surgical procedures on their anxiety-a systematic review. Journal of Clinical Nursing, 23(7-8), 940-954

Coyne, I. (2006) Consultation with children in hospital: children, parents' and nurses' perspectives. Journal of clinical nursing, 15(1), 61-71.

Coyne, I. \& Kirwan, L. (2012) Ascertaining children's wishes and feelings about hospital life. Journal of Child Health Care, 16(3), 293-304.

Coyne, I. \& Carter, B. (2018) (eds) Being participatory; Researching with Children and Young people. Switzerland: Springer

Coyne, I. \& Gallagher, P. (2011) Participation in communication and decision-making: children and young people's experiences in a hospital setting. Journal of Clinical Nursing, 20(15-16), 2334-2343.

Dai, Y. \& Livesley, J. (2018) A mixed-method systematic review of the effectiveness and acceptability of preoperative psychological preparation programmes to reduce paediatric preoperative anxiety in elective surgery. Journal of Advanced Nursing, 74(9), 2022-2037.

Dalley, J.S. \& McMurtry, C.M. (2016) Teddy and I get a check-up: a pilot educational intervention teaching children coping strategies for managing procedure-related pain and fear. Pain Research and Management.

Dokter, D. \& De Zárate, M.H. eds., (2016). Intercultural arts therapies research: Issues and methodologies. Oxon, Routledge

Duff, A.J., Gaskell, S.L., Jacobs, K. \& Houghton, J.M., (2012). Management of distressing procedures in children and young people: time to adhere to the guidelines. Archives of Disease in Childhood 97 (1) [ https://adc.bmj.com/content/97/1/1 accessed 05/02/17]

Gallagher, L.A. \& Gallagher M (2008) Methodological Immaturity in Childhood Research? Thinking through participatory Methods. Childhood 15 (4) 499-516

Haijes, H.A. \& van Thiel, G.J., (2016). Participatory methods in pediatric participatory research: a systematic review. Pediatric research, 79(5), 676-683

Hedén, L., von Essen, L. \& Ljungman, G. (2016) The relationship between fear and pain levels during needle procedures in children from the parents' perspective. European Journal of Pain, 20(2), 223-230.

Holmes, C.A., (1992). The drama of nursing. Journal of Advanced Nursing, 17(8), 941-950. 
Jaaniste, T., Hayes, B. \& Von Baeyer, C.L. (2007) Providing Children with Information about Forthcoming Medical Procedures. Clinical Psychology and Science Practice 14 (2) 124-143

Lambert, V., Glacken, M. \& McCarron, M. (2008). 'Visible-ness': the nature of communication for children admitted to a specialist children's hospital in the Republic of Ireland. Journal of Clinical Nursing, 17(23), 30923102.

Lambert, V., Glacken, M. \& McCarron, M. (2013) Meeting the information needs of children in hospital. Journal of Child Health Care, 17(4), 338-353.

Livesley, J. \& Long, T. (2013) Children's experiences as hospital in-patients: Voice, competence and work. Messages for nursing from a critical ethnographic study. International journal of nursing studies, 50(10), 12921303.

McMurtry, C.M., Chambers, C.T., McGrath, P.J. \& Asp, E. (2010) When "don't worry" communicates fear: Children's perceptions of parental reassurance and distraction during a painful medical procedure. Pain, 150(1), 52-58.

Moore, L. \& Kirk, S. (2010) A literature review of children's and young people's participation in decisions relating to health care. Journal of Clinical Nursing, 19(15-16), 2215-2225.

Murphy, F. (2009) Act, scene, agency: The drama of medical imaging. Radiography 15, 34-39

Noel, M., McMurtry, C.M., Pavlova, M. \& Taddio, A., (2018) Brief Clinical Report: A Systematic Review and Meta-analysis of Pain Memory-reframing Interventions for Children's Needle Procedures. Pain Practice, 18(1), 123-129.

Norris, J. (2000) Drama as research: Realizing the potential of drama in education as a research methodology. Youth Theatre Journal, 14(1), 40-51.

O'Kane, C. (2000) The Development of Participatory Techniques Facilitating Children's Views about the Decisions which Affect Them. In P. Christensen and A. James (eds) Research with Children: Perspectives and Practices, pp. 136-59. London: Falmer Press.

Taylor, C., Sellick, K. \& Greenwood, K. (2011) The influence of adult behaviors on child coping during venipuncture: A sequential analysis. Research in Nursing \& Health, 34(2), 116-131.

Veale, A. (2005). Creative methodologies in participatory research with children. Researching children's experience: Approaches and Methods, 253-272.

Yardley, K (2005) Role Play. In J.Smith, R. Harre \& L. Van Langenhive (Eds) Rethinking Methods in Psychology London: Sage 106-121

Yardley, A (2014) Children describing the world: Mixed-method research by child practitioners developing an intergenerational dialogue. Educational \& Child Psychology 31 (1) 48-62 
Table 1: The different scenes outlined for the drama activities.

Scene 1: Someone has knocked their head playing football and need an X-ray. They are feeling a bit sick and have a headache. They have not had an X-ray before. Their mum is with them.

Scene 2: Someone has cut their finger on a sharp stone and needs to have it examined and glued/stitched in the accident and emergency department. They are with their mum and dad.

Scene 3: Someone has had headaches for a while and needs a scan. They have come to the scan department today and are not sure what will be happening. They have come with their Dad and sister.

Scene 4: Someone has been feeling sick and dizzy for a few weeks and their doctor has sent them to the hospital for a blood test. They have not had a blood test before and they are with their Mum. 
Table 2: Drama workshop participants

\begin{tabular}{|l|l|}
\hline Workshop $\mathbf{1}$ ( $\mathbf{n}=\mathbf{8})$ & Workshop $\mathbf{2}(\mathbf{n}=\mathbf{7})$ \\
\hline Aged 7-14 years (4 boys, 4 girls) & Aged 8-13 years (1 boy, 7 girls) \\
\hline
\end{tabular}




\section{Figure 1: Visual Minutes of drama workshop|}

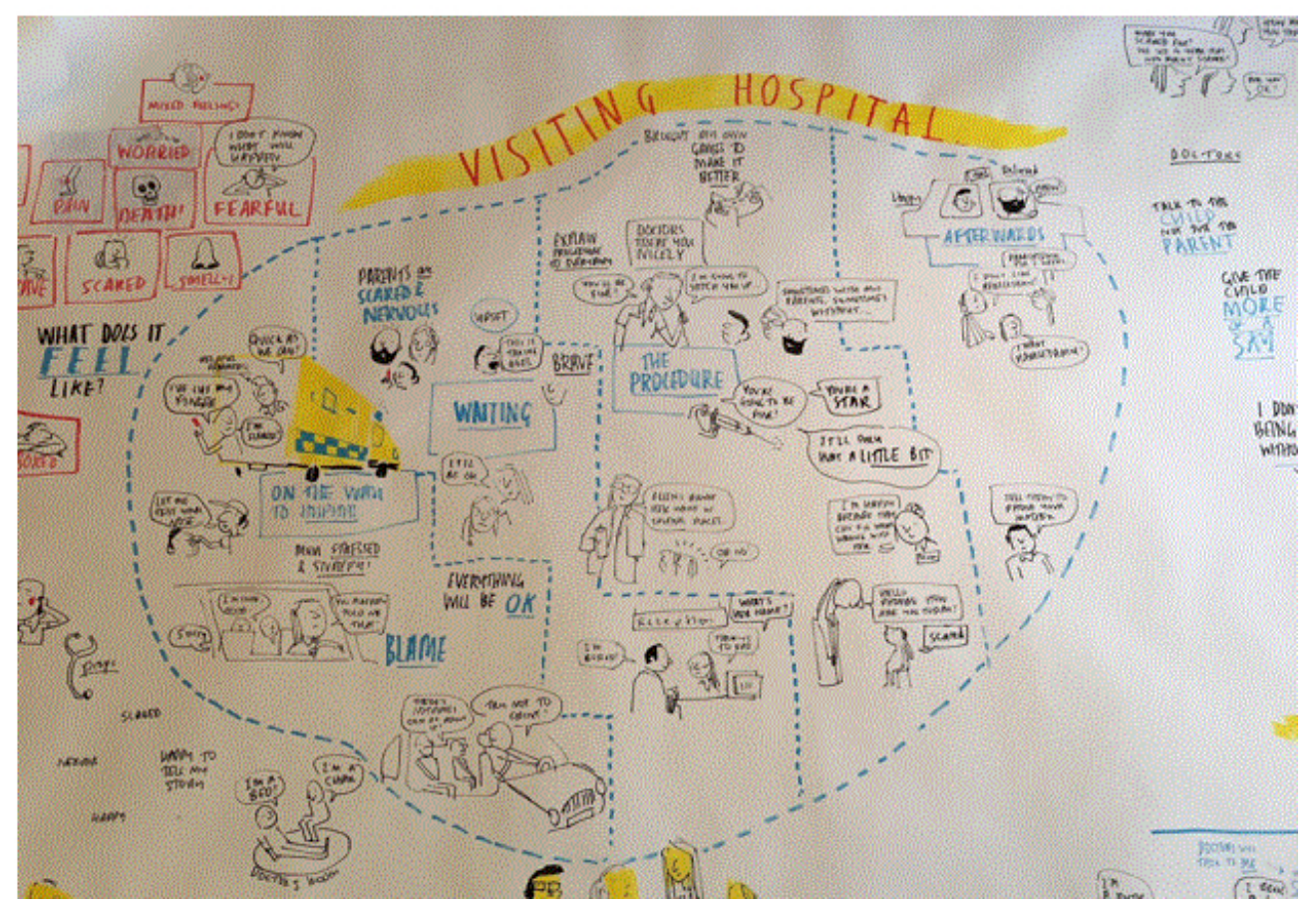

Figure 1: Visual minutes

$223 \times 165 \mathrm{~mm}(72 \times 72 \mathrm{DPI})$ 